\title{
Noonan Syndrome Eye Signs: A Case Report
}

Taha AYYILDIZ1

${ }^{1}$ Department of Ophthalmology, Ahi Evran University, Kırşehir, Turkey.

\section{ABSTRACT}

Noonan syndrome (NS) is a rare autosomal dominant inherited disease characterized by short stature, facial abnormalities, congenital heart defects, and urogenital malformations. It is important to know that eye signs are more frequent in patients and usually occur as hypertelorism, downward-sloping palpebral fissures, epicentral folds, ptosis, fracture defects, strabismus, amblyopia, nystagmus, coloboma, keratoconus, and, rarely, cataracts. A 14-year-old male patient suspected of having NS due to inferior pectus excavatum and diagnosed with NS on genetic evaluation was referred to the clinic to evaluate the ocular findings obtained from the ophthalmic examination.

This rare syndrome is characterized by heterogeneous group involvement in various organs and requires a multidisciplinary approach to ensure early diagnosis and treatment of multiple malformations.

Key words: Eye signs, genetic evaluation, Noonan syndrome

\section{INTRODUCTION}

The disease is characterized by skeletal anomalies such as short stature, mane neck, clinodactyly, pectus excavatum and/or carinatum, low and posteriorly rotated ears, triangular face, small maxilla, micrognathia, high palate, dental malocclusion, congenital heart defects, renal malformations, lymphatic system pathologies, puberty delay, hearing loss, moderate mental retardation, and urogenital malformations. More rarely, the disease may be accompanied by psychomotor developmental deficits. Moreover, thrombocytopenia and dissemination of clotting factors (VIII, XI, and XII) are common in these patients, especially in childhood. In a small number of the cases, pigmentation disorders such as nevus, café-au-lait spots, and lentigo occur. It is important to know that eye signs are more frequent in these patients, and usually occur as hypertelorism, downset palpebral fissures, epicentral folds, ptosis, fracture defects, strabismus, amblyopia, nystagmus, coloboma, keratoconus, and cataracts (1-3).

Noonan syndrome (NS) is a homogeneous but genetically heterogeneous disease. Approximately half of the cases are sporadic, and an autosomal dominant transition is observed in a significant part. Autosomal recessive cases have also been reported rarely. Diagnosis is clinically feasible, but if possible, genetic testing is important. Approximately $50 \%$ of these patients have "missense" mutations in the protein tyrosine phosphatase non-receptor type 11 (PTPN11) gene on the long arm of chromosome 12 (4-6). This enzyme is an intracellular signal for cytokines and hormones that regulate the growth and development processes $(7,8)$.

This std aimed to report the case of a 14-year-old man who was suspected of having NS due to inferior pectus excavatum and diagnosed with NS on genetic evaluation.

Correspondence:

Taha AYYILDIZ

Ahi Evran Mahallesi, Yavuz Sultan Selim Bulvarı, Aybars Apartmanı, Daire 9, Kırşehir Merkez 34000 Kırşehir, Türkiye.

e-mail: obirtahadir@hotmail.com 


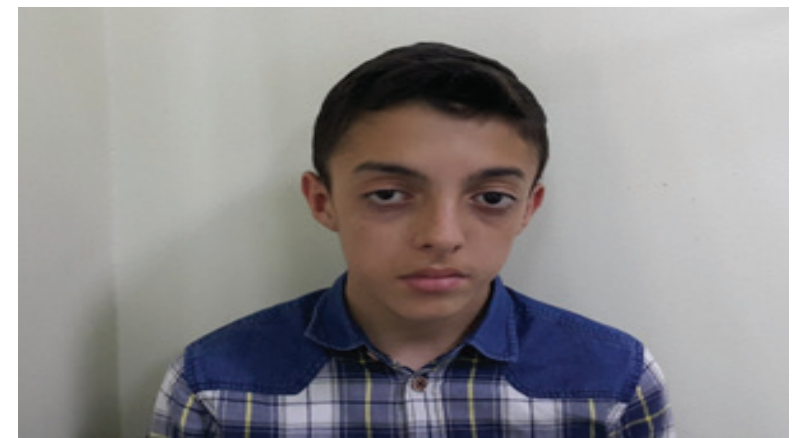

FIGURE 1: A 14-year-old male patient with Noonan syndrome (Permission for using this photograph was obtained from the patient's family).

\section{CASE}

A 14-year-old male patient with suspected NS due to inferior pectus excavatum and diagnosed with NS on genetic evaluation was referred to the clinic for the evaluation of ocular findings. The patient's height was $153 \mathrm{~cm}$ (percentile 3\%-10\%), and the weight was $40 \mathrm{~kg}$ (percentile 3\%-10\%). Cranial tomography and ultrasonography of the abdomen showed no features. Echocardiography revealed mild mitral regurgitation and dilatation of the aortic root. The patient's karyotype 46 was identified as XY. The mother and father were not related. No trait was found in the family history.

The best corrected visual acuity was $0.2(+1.5,-2.25,10$ degrees) in the right eye and 10/10 in the left eye according to the patient's Snellen syncope. Right-sided hypertropia (10 $\Delta d$ ) and exotropia $(20 \Delta d)$ accompanied by ptosis (MRD +2$)$ and downward-sloping palpebral fissures were present. He also had distinctive facial asymmetry, as he held his head up and to the left to ensure proper binocular vision. The interpupillary distance was measured as 71 $\mathrm{mm}$ and evaluated for hypertelorism (Figure 1). Eye movements and convergence were evaluated as normal. The levator function was $15 \mathrm{~mm}$ in each eye. No additional pathology was found on biomicroscopic and fundoscopic evaluation. Intraocular pressures were measured with Goldmann applanation tonometry: $12 \mathrm{~mm} \mathrm{Hg}$ in the right eye and $17 \mathrm{~mm} \mathrm{Hg}$ in the left eye.

\section{DISCUSSION}

NS is a rare inherited autosomal dominant inherited disease. Male Turner syndrome, Turner-like syndrome, or Turner syndrome with normal karyotype was defined as a specific syndrome in 1963 by physician Jacqueline Noonan and subsequently received his name (9). The incidence of NS is different and ranges from 1/1000 to $1 / 2500$ live births $(10,11)$.

Although the NS diagnosis can be made on the basis of the clinical evaluation, it is important to perform genetic testing if possible. Approximately $50 \%$ of these patients have mutations in the PTPN11 gene, which is responsible for the tyrosine phosphatase enzyme found on chromosome (12). This enzyme is an intracellular signal for cytokines and hormones that regulate the growth and development processes $(7,8)$. Although NS may occur sporadically, it is thought that the genetic background is an autosomal dominant transition, with maternal predominance.

In NS, ocular abnormalities are quite common and present in about $95 \%$ of cases $(1,8)$. The most common manifestations are refraction defects (61\%), strabismus (48-63\%), and amblyopia $(33 \%)(2,8)$. Other malformations of the coloboma and retina occur quite rarely (10\%) and are usually associated with PTPN11 gene mutations $(8,12)$. As evident from the present case, the ophthalmologist can be an extremely important link in the diagnosis when the frequency of ocular involvement is taken into account.

Lee et al (1) evaluated the frequency of ophthalmic findings in 58 series of patients and found hypertelorism (74\%), antimongoloid eyelids (38\%), epicentral folds (39\%), ptosis (48\%), strabismus (48\% 61), amblyopia (33\%), nystagmus (9\%), marked corneal nerves (46\%), anterior stromal dystrophy (4\%), cataracts (8\%), panuveitis (2\%), and myelinated nerve fibers (20\%), such as drusen and coloboma. Hypertelorism, antimongoloid eyelids, ptosis, strabismus, and anisometropic amblyopia reported in the present case are compatible with the literature.

Although NS may be easy to diagnose because it is contained in an extremely heterogeneous group of abnormalities, a scoring system may be required because of variations in the appearance of these changes (12). This scoring system can be quite helpful in early diagnosis and treatment of many anomalies (Table 1).

Definitive NS: 1) one major or two minor findings accompanying typical facial findings, 2) two major or three minor findings accompanying suspicious facial findings

In addition to the typical facial features in the present case, inferior pectus excavatum, short stature (P3-P10), mitral regurgitation, 
TABLE 1: Noonan syndrome scoring chart.

\begin{tabular}{lll}
\hline & A: Major & B: Minor \\
\hline Face & Typical dysmorphology & Suspected dysmorphology \\
Heart & Pulmonary stenosis, cardiomyopathy & Other defects \\
Height & $<$ P3* & $<$ P10* \\
Thorax & Pectus carinatum/excavatum & Enlarged thorax \\
Family history & Noonan syndrome with definite diagnosis in & Noonan syndrome with suspicious diagnosis in \\
& first-degree relatives & first-degree relatives \\
Other & Mental retardation, undescended testis and & These changes are lighter form \\
& lymphatic dysplasia & \\
\hline * P3 and P10 age-specific percentiles (normal range P3-P97). &
\end{tabular}

and dilatation accompanied by dilatation of the aortic root are sufficient to confirm the definite diagnosis of NS. The patient's genetic evaluation result was also shown to be PTPN11 mutation.

Several genes leading to this syndrome (PTPN11, SOS1, RAF1, and KRAS) have been identified $(13,14)$. Moreover, neurofibromatosis and NS coexistence have also been shown due to mutations in the neurofibromin gene located on the long arm of chromosome 17 $(15,16)$.

The present case was evaluated with NS accompanied by hypertelorism, antimongoloid eyelids, low and back displaced ears, inverted triangular head shape, thin jaw, curly hair shape, and 46, XY karyotypes. XO/XY mosaicism, fetal hydantoin syndrome, fetal myolin syndrome, and fetal alcohol syndrome should also be considered in the differential diagnosis of this syndrome (17). Growth hormone therapy has been found to be beneficial for these patients in recent years (20).

Congenital heart disease was reported in $68 \%$ of patients with this syndrome. The most common cardiac anomaly is pulmonary stenosis. This heart anomaly is associated with NS because of the presence of pulmonary stenosis in half of the patients $(19,20)$. Only mild mitral insufficiency and dilatation of the aortic root were found in the present case.

In conclusion, this study aimed to draw attention to eye findings in a 14-year-old male patient with NS, which is a rare genetic disorder.
This rare syndrome is characterized by extremely heterogeneous group involvement in various organs and requires a multidisciplinary approach to ensure early diagnosis and treatment of multiple malformations.

\section{REFERENCES}

1. Lee NB, Kelly L, Sharland M. Ocular manifestations of Noonan syndrome. Eye. 1992;6:328-34.

2. Reynolds DJ, Rubin SE, Fox J, Kodsi SR. Ocular manifestations of Noonan syndrome in the pediatric patient. J AAPOS. 2004;8:282-3.

3. Randolph JC, Sokol JA, Lee HB, Nunery WR. Orbital manifestation of Noonan Syndrome. Ophthal Plast Reconstr Surg. 2011;27:160-3.

4. Sznajer $Y$, Keren B, Baumann C. The spectrum of cardiac anomalies in Noonan syndrome as a result of mutations in the PTPN11 gene. Pediatrics. 2007;119:1325-331.

5. Lemire EG. Noonan syndrome or new autosomal dominant condition with coarctation of the aorta, hypertrophic cardiomyopathy, and minor anomalies. Am J Med Genet. 2002;113:286-290.

6. Noonan JA. Hypertelorism with Turner phenotype. A new syndrome with associated congenital heart disease. Am J Dis Child. 1968;116:373-380.

7. Neel BG, Gu H, Pao L. SH2 domain-containing tyrosine phosphatases in cell signaling. Trends. Biochem Sci. 2003;28:284-93.

8. Tartaglia $\mathrm{M}$, Cordeddu V, Chang $\mathrm{H}$. Paternal germline origin and sex-ratio distortion in transmission of PTPN11 mutations in Noonan syndrome. Am J Hum Genet. 2004;75:492-7.

9. Noonan JA, Ehmke DA. Associated non-cardiac malformations in children with Congenital heart disease. J Paed. 1963;63:46870.

10. Allanson JE. Noonan syndrome. J Med Genet. 1987;24:9-13.

11. Sharland M, Burch M, Patton MA. A clinical study of Noonan syndrome. Arch Dis Child. 1992;67:178-83. 
12. Romano AA, Allanson JE, Dahlgren J, Gelb BD, Hall B, Pierpont ME. Noonan Syndrome: Clinical features,Diagnosis, and Management Guidelines. Pediatrics. 2010;126:746-59.

13. Nystrom AM, Ekvall S, Allanson J. Noonan syndrome and neurofibromatosis type I in a family with a novel mutation in NF1. Clin Genet. 2009;76:524-534.

14. Jorge AA, Malaquias AC, Arnhold IJ. Noonan syndrome and related disorders: a review of clinical features and mutations in genes of the RAS/MAPK pathway. Horm Res. 2009;71:185193.

15. Lemire EG. Noonan syndrome or new autosomal dominant condition with coarctation of the aorta, hypertrophic cardiomyopathy, and minor anomalies. Am J Med Genet. 2002;113:286-290.
16. van Der Burgt I, Brunner H. Genetic heterogeneity in Noonan syndrome: evidence for an autosomal recessive form. Am J Med Genet. 2000;94:46-51.

17. Jones KL. Noonan syndrome. In: Smith's Recognizable Patterns of Human Malformation. 6th ed, Elsevier Saunders, Philadelphia. 2006;124-5.

18. Noonan JA, Raaijmakers R, Hall BD. Adult height in Noonan syndrome. Am J Med Genet. 2003;123:68-71.

19. Aydin A, Yilmazer MS, Gurol T. Sudden death in a patient with Noonan syndrome. Cardiol Young. 2011;21:233-4.

20. Chevallier S, Cook S, Goy JJ. Heart failure in a patient with Noonan syndrome. Circulation. 2011;123:629-30. 